\title{
An Evaluation of Cold Climate Variable Capacity Air-Source Heat Pumps in Canadian Residential Buildings Using an Enhanced Component Model
}

\author{
Stéphanie Breton ${ }^{1}$, Justin Tamasauskas ${ }^{1}$, Martin Kegel ${ }^{1}$ \\ ${ }^{1}$ CanmetENERGY-Natural Resources Canada, Varennes, Canada
}

\begin{abstract}
Cold climate heat pumps integrating variable-capacity technologies can offer important energy savings for residential buildings across Canada. However, there is a lack of detailed and reliable performance data and models available to assess their true impact on building energy performance, especially when accounting for performance variations with compressor speed, operational sequences such as defrost, and on/off cycling. This paper presents an enhanced variable capacity heat pump (VCHP) component model developed in TRNSYS, which captures these unique short-term performance characteristics while remaining suitable for system-level simulations. The model is combined with detailed singlefamily housing models in five regions across Canada to assess the energy performance of this system.
\end{abstract}

Annual system simulations show that the substitution of HVAC system conventional in Canada for VCHPs has a strong potential to reduce mechanical system energy use. Annual savings average 33\% for split systems and 54\% for centrally-ducted systems, driven by the ability of VCHPs to meet space-heating loads at low ambient temperatures and to efficiently modulate across a wide range of heating and cooling loads, with higher part-load efficiencies than conventional heat pumps. A closer look at the VCHP performance during a typical winter day in Montreal highlights the importance of accounting for the short-term effects of defrost and recovery cycles on the heating capacity and power. A comparison with a conventional modelling strategy shows that the daily peak power can be underestimated by as much as $40 \%$ with these approaches. The use of more detailed models, as shown in this study, is necessary to support the adoption of this promising technology and to better understand the prospective grid impact.

\section{Introduction}

The built environment is a key focus area as the world transitions towards more sustainable, decarbonized energy systems. Similar to trends observed globally, residential buildings comprise $17 \%$ of secondary energy use and GHG emissions in Canada, with over $60 \%$ of this total directed towards space heating and cooling (NRCan, 2018). Effectively reducing the energy used to heat and cool buildings is both a major challenge and a significant opportunity to develop and deploy low-carbon technologies.
Heat pumps have been recognized as essential elements of low energy buildings, and offer several important benefits including:

1. Efficiently addressing space heating and cooling,

2. Facilitating the integration of renewable energy with the building mechanical system, and

3. Linking the thermal and electrical networks of the building to provide peak management capabilities.

In particular, air-source heat pumps (ASHPs) can be used as an efficient and economical means of satisfying building space conditioning needs. However, ASHPs in cold climates suffer from significantly degraded heating performance at lower ambient air temperatures, reducing energy savings. Cold climate heat pumps, leveraging variable-capacity technologies, have recently experienced increased growth in the North American market. These variable capacity heat pumps (VCHPs) use larger outdoor heat exchanger coil, variable-speed fans and inverterdriven compressors to meet space-heating loads at low ambient temperatures, while still efficiently modulating to lower speeds and lower capacities during warmer conditions and in cooling mode (Sager et al., 2018). This technology can bring new levels of efficiency, comfort and versatility to space conditioning.

Properly integrating heat pumps into the built environment is critical in order to maximize their benefits. However, this process is often complex, and involves considering the interaction between the mechanical systems, building envelope, and the outdoor environment. These factors require systematic analysis to maximize system benefits and spur growth in the heat pump market. Moreover, accurately assessing the energy performance of VCHPs is challenging due to a lack of data and suitable heat pump models or performance curves.

Several studies have previously examined the integration of heat pumps into single-family residential housing in Canada. Kegel et al. (2012) performed a detailed simulation study to examine the energy and economic performance of heat pump systems for several housing vintages in Toronto. Tamasauskas et al. (2013) built upon this work by examining the potential of heat pump systems as a pathway to low-energy homes. While both these studies provided a rigorous basis for system analysis, the simulation method was based on simplified on/off controls of a single-speed heat pump, and did not take into account the significant impacts that cycling, defrost, and part-load operations may have on overall 
energy use. The TRNSYS v.17 standard library includes only single- and dual-speed air source heat pump models, which are not adapted to variable capacity modelling (Klein et al., 2014). These models also lack the ability to represent key transients including defrost and start-up sequences. New approaches are needed to better represent these effects and quantify their impact on energy use.

The main research contributions of this paper are the development of an enhanced VCHP model that characterizes key short-term heat pump features typically not included in existing models (e.g. defrost and start-up), and the subsequent application of this new model to annual system simulations. First, the dynamic heat pump model developed by St-Onge (2018) is introduced and used as a basis for several key modifications that better facilitate both short- and long-term system simulations. This new heat pump model is then integrated with detailed models of newly constructed single-family housing in five regions across Canada. Results are presented from the energy perspective to assess the potential of these systems in different climates. System performance is examined at several temporal resolutions to highlight the capabilities of the modified heat pump model and the importance of including short-term performance characteristics in the system analysis.

\section{VCHP characteristics and models}

\section{General performance characteristics of VCHP}

While VCHPs offer significant energy saving potential, it is important to recognize the impact of several of their inherent performance characteristics. These include their ability to modulate capacity and their defrosting operation. Variable-speed compressor technology allows heat pumps to vary their cooling and heating capacity in response to a reduction or an increase in spaceconditioning load. The frequency of the electric supply to the motor is varied, changing the rotational speed of the compressor and thus the refrigerant flow. This precise load matching results in less on/off cycling compared to single-speed ASHPs, allowing to more smoothly meet building thermal loads. The wide range of capacity modulation enabled by the inverter-driven compressor also results in higher part-load efficiencies. Generally, the COP of VCHPs increases as the compressor speed is reduced - as identified in the part-load model for inverterdriven heat pumps presented by Filliard et al. (2009).

Another important aspect of heat pump operation is the need for defrosting. Under certain combinations of outdoor conditions (air and coil temperatures, relative humidity), frost can build up on the evaporator coil during heating operation. To avoid frost accumulation that would degrade heat pump performance, ASHPs then go into defrost mode. Most heat pumps employ a reverse cycle defrost strategy, where the cycle is temporarily reversed by changing the refrigerant flow using a reversing valve. The outdoor unit then acts as the condenser and the heat pump is in cooling mode, removing heat from the building space to melt the ice on the outdoor coil. This standard VCHP behaviour is associated with a temporary supply of colder air in the conditioned space, which affects the heating load and energy use. At warmer ambient temperatures, frost formation is not common, either because the evaporator coil are warm enough, or the heating cycles are short enough such that the outdoor air will melt the frost during off cycles if necessary.

At the end of defrost, the heat pump goes back into heating mode, but cycle components need to be reheated and the pressure difference between the evaporator and the condenser must be built up. This recovery period is characterized by transitory effects in the refrigerant cycles and the heat exchangers, which temporarily limit the heat output and delay meeting the indoor temperature setpoint. Furthermore, when the defrost cycle is completed, the heat pumps have a tendency to operate at maximum speed for a short period, which is associated with a sharp increase in power draw. This control strategy is likely employed by heat pump manufacturers to recover more rapidly from the momentarily drop in indoor temperature that occurs while the heat pump undergoes defrost. Some researchers (Filliard et al., 2009) take into account defrost by applying a degradation coefficient to the heating capacity in their models, but this approach fails to capture peaks in electrical demand, which can have a noticeable impact on the electrical grid with widespread adoption.

\section{Type 3254 - First VCHP model}

The widespread adoption of VCHPs is hindered by limited available performance data and a lack of tools to evaluate their energy saving potential. On these grounds, St-Onge (2018) conducted detailed performance testing on a variable capacity mini-split ASHP and used the test results to develop a new component model to better estimate VCHP performance in TRNSYS. The newly developed Type 3254 makes use of a detailed performance map of the heat pump in heating mode, which incorporates capacity and power at different compressor speeds, and ambient and zone air temperatures. This performance mapping captures the key capacity modulation characteristics described above and contribute to modelling VCHP more accurately than by using manufacturer data available only at rated frequency.

Additionally, the TRNSYS component model developed by St-Onge allows for simulation of the heat pump defrost cycles. Identifying the actual defrost strategy is a challenging procedure, with different laboratory historically getting different defrost test results for the same equipment while defrost control algorithms (timed defrost, adaptive defrost, ambient and coil temperature difference) are often proprietary to each heat pump manufacturer and model (and generally not made available to the public). In St-Onge's model, the defrost cycles are characterized by parameters such as defrost duration, cycle frequency and length of recovery period, which are either constants or linearly dependant on outdoor air temperature. Extensive experimental testing estimated typical five-minute-long defrost cycles, occurring every 2.5 hours and followed by a thirty-minute recovery period - values in accordance with the testing conducted by Sager et al. (2018). Following defrost, the heating capacity is gradually increased over the recovery 
period using an exponentially decaying penalty factor. To account for the low probability of entering defrost mode at warm ambient conditions, a parameter denoted defrost cutoff temperature is introduced. If the outdoor air temperature is above the cutoff $\left(5^{\circ} \mathrm{C}\right.$ used here) for more than half of the cycle duration ( 2.5 hours), defrost is not initiated. This model has been extensively validated using detailed experimental data from testing under part-load and full-load operations in various environmental conditions. The complete details of this model and its validation are outlined in St-Onge (2018).

\section{Type 3255 - Improved VCHP model}

The TRNSYS Type 3254 component model is modified and improved in this paper to facilitate system-level simulation. The first key modification made to the VCHP component model concerns the defrost mechanism. As explained above, heat pumps typically use a reverse defrost strategy during which the indoor unit cools the space to melt the frost on the outdoor coil. This temporary cooling was not modelled in Type 3254 .

Manufacturer data regarding performance degradation during defrost cycles is seldom available. As such, in this study, rated values for cooling operation are used to estimate the power consumption and the space cooling rate during defrost. Only sensible cooling is taken into account during reverse defrost cooling. Defrost cycles are certainly the most challenging aspect of detailed modelling of VCHPs and deserve further investigation beyond the current study to more accurately account for the defrost trigger and control mechanisms (e.g. ambient relative humidity dependence) as well as the performance degradation due to defrost.

To properly estimate the energy savings associated with VCHPs, one must also accurately represent its power consumption. As highlighted above, this becomes increasingly important to eventually assess the grid impact of widespread heat pump adoption. A spike in power draw, corresponding to the maximum compressor frequency, is characteristic of startup behaviour for many VCHPs. The enhanced Type 3255 component model accounts for a spike in compressor frequency and power both when the heat pump turns on and when it comes out of defrost. The importance of this feature is shown in a later short-term performance analysis.

It is important to note that emphasis is put on the heating mode because the current model was developed to include capacity and efficiency at different compressor speeds in this mode only. This is motivated by test data availability and by the importance of heating in the Canadian climate.

\section{Control strategy}

In addition to including the key aspects of VCHP performance identified above, it is also important to appropriately model how these capabilities are activated. The control strategy used to properly simulate phenomena such as capacity modulation and defrost and startup sequences with Type 3255 is explained next.
In a typical air-to-air heat pump simulation model, a thermostat outputting on/off control functions according to setpoints and deadbands would be used to start or stop the unit as required. However, in this study, a PID controller (Type 23) is used to control the VCHP by sending a frequency signal as an input to Type 3255 as represented in Figure 1a. The control signal can vary between the heat pump minimum and maximum frequencies. Should the control signal be below a set minimum, the heat pump remains in standby mode for that time step. This input is then divided by the rated frequency (a user-provided parameter in Type 3255) and used as a normalized frequency value to interpolate the VCHP performance data file. The available heating capacity and power as well as the outlet air temperature and relative humidity to be supplied to the space are then obtained directly from the model.

In cooling mode, the control strategy adopted is similar to what is described in the work of Kegel et al. (2014) and pictured in Figure 1b. The available total and sensible cooling capacity and heat pump power in cooling mode is extracted from the VCHP performance data file as a function of outdoor and indoor ambient temperatures only (no frequency dependence). The capacity of the VCHP in cooling mode is modulated with a PID controller according to the estimated percent cooling demand to meet the specified setpoint. This cooling load is then applied to the air stream using the Type 693 component to calculate the resulting supply air conditions.

To properly account for part-load and cyclic operation, the power consumption from the unit must be corrected since the cooling aspect of Type 3255 is identical to the conventional ASHP model. Above the minimum partload ratio (ratio of the minimum to the maximum cooling capacity), the variable-frequency compressor permits modulation of the heat pump. The part-load performance under these conditions is calculated using the inverterdriven heat pump part-load curve deduced from data from the Swedish Energy Agency (Filliard et al., 2009). The indoor fan is estimated to have a constant power draw throughout this operating range. Below this minimum turndown ratio, the heat pump is assumed to be cycling on/off. Under this regime, the part-load performance is calculated based on a modified version of the curve obtained from the National Energy Code of Canada for Buildings (NECB) (CCBFC, 2015). The indoor fan is assumed to follow the same cyclic operation and its power consumption is calculated using the estimated percent cooling demand.

\section{Auxiliary heating operation}

Cold climate heat pumps are commonly integrated in homes equipped with auxiliary heating equipment. These can consist of electric heat strips in the ductwork for central systems, or electric baseboards in non-ducted configurations. In the simulations, the auxiliary heaters in both cases have a setpoint slightly lower than that of the heat pump, to prioritize heat pump operations. However, when the heat pump cannot operate because the ambient conditions fall outside of its operating range, the auxiliary 


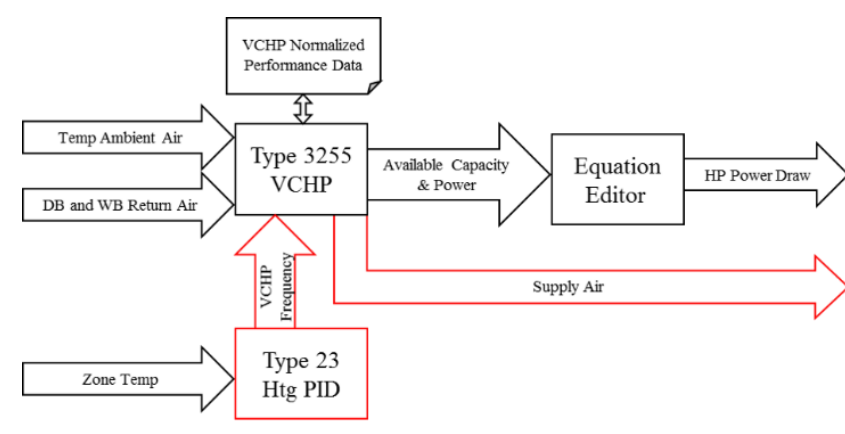

a) In heating mode

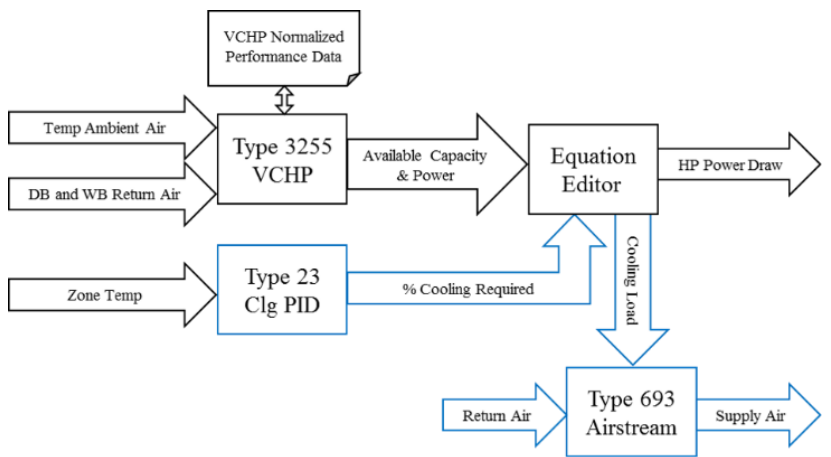

b) In cooling mode (Kegel et al, 2014)

Figure 1: VCHP integration and control strategy

setpoint is the same as that of the heat pump.

During defrost, heat from the building is absorbed and rejected outside, which can adversely affect indoor comfort. The split ASHP system modelled is not equipped with internal heating elements to offset this effect, and rather relies on auxiliary electric baseboards to maintain the temperature setpoint in the zone. Centrally ducted systems rely on an auxiliary duct heater that turns on when defrost mode is activated to temper supply air temperatures in order to avoid thermal discomfort.

\section{System simulation}

To assess the performance of the improved VCHP model, annual system simulations are performed in TRNSYS v.17 (Klein et al., 2014) by combining the model with detailed base-case housing energy models for five regions across Canada. Appropriate CWEC weather files are used and a 2.5-minute time step is selected for the simulation. The energy savings of VCHPs can then be assessed for residential buildings in different climate zones.

\section{Base-case housing models}

The housing energy models are based on the Canadian Centre for Housing Technology (CCHT) twin test houses located in Ottawa, ON. These homes were designed to be representative of typical single-family housing in Canada and consist of two above-ground floors and a finished basement with a total heated floor area of $284 \mathrm{~m}^{2}$. The models were updated to meet the 2010 National Building Code of Canada (NBC) minimum energy efficiency performance requirements for the respective provinces (NRC, 2010). Key housing characteristics for new constructions in selected regions are included in Table 1. Additional modelling details and assumptions are summarized by Kegel et al. (2017).

Standard TRNSYS components were used to model the building HVAC systems. The heating and cooling capacity of the HVAC equipment were modulated constantly to maintain the zone temperature setpoints $\left(21^{\circ} \mathrm{C}\right.$ in heating and $23^{\circ} \mathrm{C}$ in cooling), while accounting for reduced efficiencies when not operating at full load over a time step. Since the ability to model part-load behaviour is not inherent to most standard TRNSYS component models, the procedure detailed in Kegel et al. (2014) is used. The part-load performance of the fuelfired heaters, air conditioning units and fans is calculated using curves from the NECB (CCBFC, 2015).

\section{Heat pump system integration}

The base-case models serve as a reference for the variable capacity heat pump integration. Newly developed Type 3255 is integrated in the housing models as a replacement for the conventional heating and cooling systems. Depending on the typical HVAC equipment installed in the base-case housing model, the integration follows that of either a ductless or a ducted air-source heat pump. Ductless split heat pumps are complemented with baseboard heating, whereas ducted central heat pumps are installed in homes typically equipped with natural gas or oil furnaces. Table 2 summarizes the rated performance of the ductless and ducted VCHP units analysed in this study, at AHRI reference conditions (Mitsubishi, 2017).

The performance data provided by the manufacturer are for heating operation without any frost and do not include performance during part-load operation. The Type 3255 VCHP component model developed better characterizes the performance of VCHPs by simulating the defrost behaviour and capturing the dynamic VCHP operation and performance. For the split systems, the performance map used in heating mode was developed by St-Onge (2018) using test data. For centrally-ducted VCHPs, the performance map was derived from available manufacturer data and part-load performance curves due to a lack of test data for this type of system integration.

\section{Results}

The results of the annual system simulations are presented for all the regions studied to assess the energy savings potential of VCHP technology compared to base cases. The performance at shorter time scales is then examined for the ductless VCHP integrated in Montreal, to facilitate an examination of short-term behaviour and a comparison with a common heat pump modelling approach.

\section{Annual energy performance}

The estimated annual energy consumption for the base case and the VCHP scenario for each region are presented next. A breakdown of the annual energy consumption for different systems is included in Table 3 for houses where the electric baseboards are coupled with a split VCHP. The heat pump integration provides a significant reduction in energy use for space heating and cooling (denoted $\mathrm{Htg} / \mathrm{Clg}$ ) - predicted to be $37 \%$ and $28 \%$ in 
Table 1: Selected regions and respective key housing characteristics

\begin{tabular}{lccccc}
\hline Region Characteristics & Halifax, NS & Montreal, QC & Toronto, ON & Vancouver, BC & Whitehorse, YK \\
\hline Heating Degree Days & 4,000 & 4,200 & 3,520 & 2,825 & 6,580 \\
Space Heating System & $\begin{array}{c}\text { Electric } \\
\text { baseboards }\end{array}$ & $\begin{array}{c}\text { Electric } \\
\text { baseboards }\end{array}$ & $\begin{array}{c}\text { Natural gas } \\
\text { furnace }\end{array}$ & $\begin{array}{c}\text { Natural gas } \\
\text { furnace }\end{array}$ & Oil furnace \\
Heating Efficiency & $100 \%$ & $100 \%$ & $92.10 \%$ & $92.10 \%$ & $85 \%$ \\
Space Cooling System & Split AC unit & Split AC unit & Central AC & Central AC & - \\
DHW Fuel & EOP $=3.3^{*}$ & COP $=3.3^{*}$ & COP $=3.5^{*}$ & COP $=3.4^{*}$ & Electric \\
\hline
\end{tabular}

*At AHRI conditions

Table 2: Characteristics of selected VCHP units

\begin{tabular}{|c|c|c|c|c|}
\hline Performance Characteristic per Region & Montreal & Toronto & Vancouver & Whitehorse \\
\hline Integration type & Ductless & Ducted & Ducted & Ducted \\
\hline Heating capacity (ton) & 1.5 & 3 & 2.5 & 3.5 \\
\hline AHRI Rated Heating COP & 4.2 & 3.7 & 3.6 & 3.5 \\
\hline AHRI Rated Cooling COP & 3.8 & 3.7 & 3.7 & 2.9 \\
\hline Minimum Operating Temperature $\left({ }^{\circ} \mathrm{C}\right)$ & -25 & -25 & -25 & -25 \\
\hline
\end{tabular}

Halifax and Montreal, respectively. The relative savings are higher in Halifax due to its maritime climate, with more moderate winters and cooler summers than Montreal, leading to a lower total annual energy consumption. The VCHP operates in heating mode for approximately 2,810 hours yearly in Montreal (2,680 in Halifax), covering $60 \%$ of the total space heating load over the year (73\% for Halifax). The VCHP in Halifax is estimated to spend about $12 \%$ less time in defrost mode than its counterpart installed in a home in Montreal. Despite replacing the existing split air conditioning unit by a similar system, savings of $50 \%$ in energy consumption for space cooling are observed in both cities. This can be explained in part by the VCHP efficiently modulating to lower loads and having a higher COP than the AC unit it replaces (4.2 vs 3.3). More importantly, the VCHP has a higher sensible heat factor (SHF) than the previous AC unit (0.84 vs 0.65), which allows for a more rapid cooling of the space, and, as a result, less time spent in cooling mode.

Table 4 presents annual energy performance for the cities with central HVAC systems. By substituting the heat pump for even less efficient systems, its integration in central systems provides more substantial energy savings. The annual energy for space heating and cooling is estimated to be reduced by over $50 \%$ in all three regions, with the majority of the savings associated with space heating. In particular, Vancouver's milder weather yields improved heating COPs and resulting energy savings primarily due to warmer ambient temperatures in the winter months. These conditions also result in the VCHP in Vancouver defrosting significantly less than in the other cities studied. Compared to the ductless integration, the centrally-ducted VCHP provides less cooling savings versus the base cases as it has characteristics comparable to the unit it replaces. The savings in fan power observed in Toronto and Vancouver can be explained by the switch from a furnace system with permanent split capacitor (PSC) single-speed motors to a heat pump with more efficient, electronically commutated motors (ECM) with variable-speed capability. In Whitehorse, the larger size VCHP implemented requires substantially higher airflows than those delivered by the oil furnace in the base case, offsetting the effects of energy efficient fans. Whereas the VCHP covers more than $95 \%$ of the heating load in both Toronto and Vancouver, this value only reaches $78 \%$ in Whitehorse. Due to the harsher climate, the fully sized auxiliary heater is used whenever the outdoor air temperature falls below the minimum operating temperature of the heat pump $\left(-25^{\circ} \mathrm{C}\right)$.

\section{Short-term performance}

The newly developed model accurately captures the unique, short-term characteristics of VCHPs such as

Table 3: Annual energy performance in Halifax and Montreal (split system)

\begin{tabular}{lcc|cc}
\hline & \multicolumn{2}{c|}{ Halifax } & \multicolumn{2}{c}{ Montreal } \\
\hline & Base Case & VCHP & Base Case & VCHP \\
\hline Heating $(\mathrm{kWh})$ & 12,460 & 7,640 & 16,090 & 11,450 \\
Cooling $(\mathrm{kWh})$ & 770 & 380 & 1,170 & 600 \\
Fans $(\mathrm{kWh})$ & 470 & 630 & 490 & 670 \\
DHW $(\mathrm{kWh})$ & 4,220 & 4,220 & 4,270 & 4,270 \\
Light/Equip $(\mathrm{kWh})$ & 9,520 & 9,520 & 9,520 & 9,520 \\
\hline Total $(\mathrm{kWh})$ & 27,440 & 22,390 & 31,540 & 26,510 \\
Total Savings $(\mathrm{kWh})$ & - & 5,050 & - & 5,030 \\
Savings Htg/Clg $(\%)$ & - & $37 \%$ & - & $28 \%$ \\
\hline
\end{tabular}


Table 4: Annual energy performance in Toronto, Vancouver and Whitehorse (central system)

\begin{tabular}{lcc|cc|cc}
\hline & \multicolumn{2}{c|}{ Toronto } & \multicolumn{2}{c}{ Vancouver } & \multicolumn{2}{c}{ Whitehorse } \\
\hline & Base Case & VCHP & Base Case & VCHP & Base Case & VCHP \\
\hline Heating $(\mathrm{kWh})$ & 13,240 & 4,920 & 10,350 & 3,410 & 29,550 & 12,030 \\
Cooling $(\mathrm{kWh})$ & 1,040 & 670 & 410 & 360 & - & - \\
Fans $(\mathrm{kWh})$ & 4,130 & 3,430 & 3,610 & 2,100 & 3,030 & 3,530 \\
DHW $(\mathrm{kWh})$ & 6,370 & 6,370 & 5,870 & 5,870 & 5,410 & 5,410 \\
Light/Equip $(\mathrm{kWh})$ & 9,520 & 9,520 & 9,520 & 9,520 & 9,520 & 9,520 \\
\hline Total $(\mathrm{kWh})$ & 34,300 & 24,910 & 29,760 & 21,260 & 47,510 & 30,490 \\
Total Savings $(\mathrm{kWh})$ & - & 9,390 & - & 8,500 & - & 17,020 \\
Savings Htg/Clg $(\%)$ & - & $51 \%$ & - & $59 \%$ & - & $52 \%$ \\
\hline
\end{tabular}

performance variations with compressor speed, cycling, and defrost operations. Examining the performance at shorter time scales highlights the impact of such behaviour. Detailed simulation results for the Montreal region are used to showcase the advantages of this enhanced VCHP model. Figure 2 provides a closer examination of system performance during a representative day in March, with outdoor air temperatures ranging from $-13^{\circ} \mathrm{C}$ to $-2^{\circ} \mathrm{C}$. The first portion of the day is associated with colder ambient air temperatures, which requires the heat pump to modulate its heating capacity by varying its compressor frequency between minimum and maximum values. The improved VCHP model implemented is able to quantify the impact of part-load operation on overall energy use by properly modelling part-load efficiency, which is higher due to capacity modulation over a wide range as compared with traditional single-speed heat pumps. During this operation, the heat pump is predicted to undergo four defrost cycles, that is once every 2.5 hours, for a period of five minutes. This results in a slight drop in indoor air temperatures as the heat pump cycle is reversed to melt the ice on the outdoor coil. The split system modelled does not automatically resort to auxiliary heating to warm the supply air during defrost, but rather relies on the electric baseboards to turn on if the space temperature decreases too much. When the heat pump comes out of defrost, the compressor runs at full speed, associated with an abrupt spike in power draw. On the other hand, the VCHP heating capacity progressively ramps up to its steady-state heating capacity, following an exponential recovery curve. The heating capacity is temporarily limited during recovery because of transitory effects occurring at both heat exchangers and in the refrigerant cycle. There is therefore a delay in reattaining the setpoint temperature of the space. The short-term performance of the VCHP shows the twofold impact of defrost on heat pump performance: heating supplied to the house decreases, while space heating demand then increases due to the temporary cooling.

As the day progresses, the outdoor air temperature rises and solar and internal gains reduce thermal demand in the house. The heat pump is then in standby mode between 10:00 and 18:00, with an associated small standby power draw. Once the thermostat sends a signal that the zone air temperature has fallen below the setpoint and the heating load can be met by the minimum capacity of the heat pump, it switches back into heating mode. When starting up, the compressor spikes to its maximum frequency, which generates a peak in power draw and in heating capacity. The compressor speed is subsequently adjusted to match the space heating load. Under certain circumstances, as highlighted in Figure 2 from 18:00 to 24:00, this $\mathrm{max} / \mathrm{min}$ frequency alternation leads to the heat pump temporarily exhibiting cycling behaviour. In fact, the capacity available at maximum compressor speed when the heat pump turns on is frequently more than is required to keep the zone temperature within the desired range, so the heat pump rapidly turns off again. This on/off cycling can be examined thanks to the improved VCHP model developed, which captures dynamic behaviour during startup. The daily operation of the VCHP in Montreal emphasizes the ability of this technology to deliver capacity below and above its nominal rated capacity by changing its compressor speed and modulating other ancillary components. The importance of properly sizing HVAC equipment is also underlined by the on/off performance of the VCHP exhibited at higher ambient air temperature.

\section{Comparison with conventional heat pump modelling}

To highlight the importance of including short-term behaviour in the system analysis, a comparison was done with a commonly employed heat pump integration and control strategy, which allows for perfect modulation of the space conditioning load. An example of this is the control strategy devised by Kegel et al. (2014) described in Figure $1 \mathrm{~b}$, used to model the cooling mode of the VCHP, which was now extended to the heating mode for this comparison. This is similar to the methodology typically used in some building simulation programs (e.g. DOE2.1). For this comparison, the VCHP was modelled using a data-driven approach, combining the conventional air-source heat pump Type 954 component model with rated performance from the manufacturer and a performance map developed from the same test data used with Type 3255. The simulation results are presented in Figure 3 for Montreal for the same winter day. As expected, the heat pump is able to better maintain the zone temperature around the specified $21^{\circ} \mathrm{C}$ setpoint and there is no periodic drop in indoor air temperatures since defrost is not modelled. The VCHP heating capacity can be seen to modulate in order to satisfy the space heating load. 


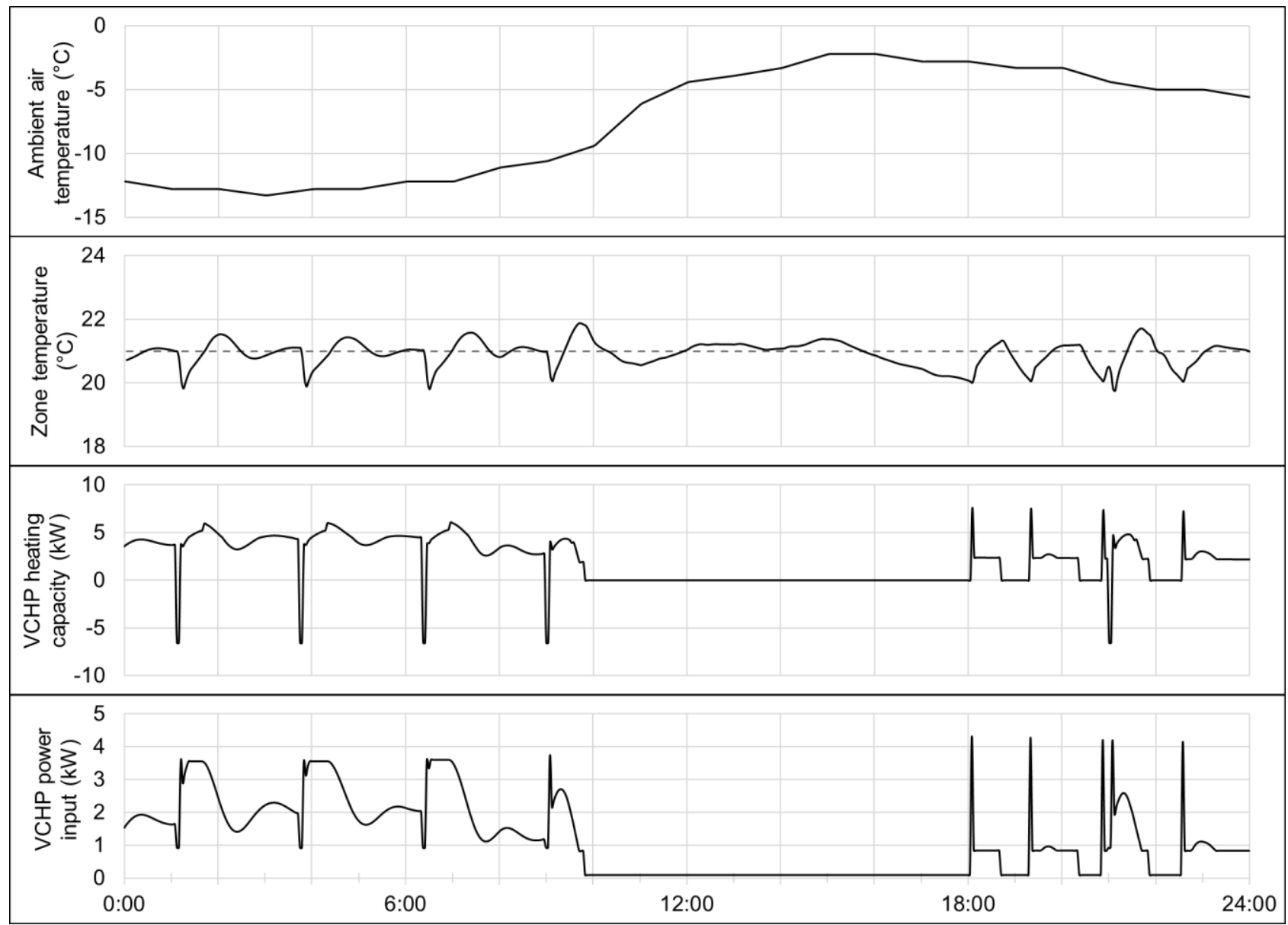

Figure 2: Simulation results for Montreal on March 11 th using Type 3255

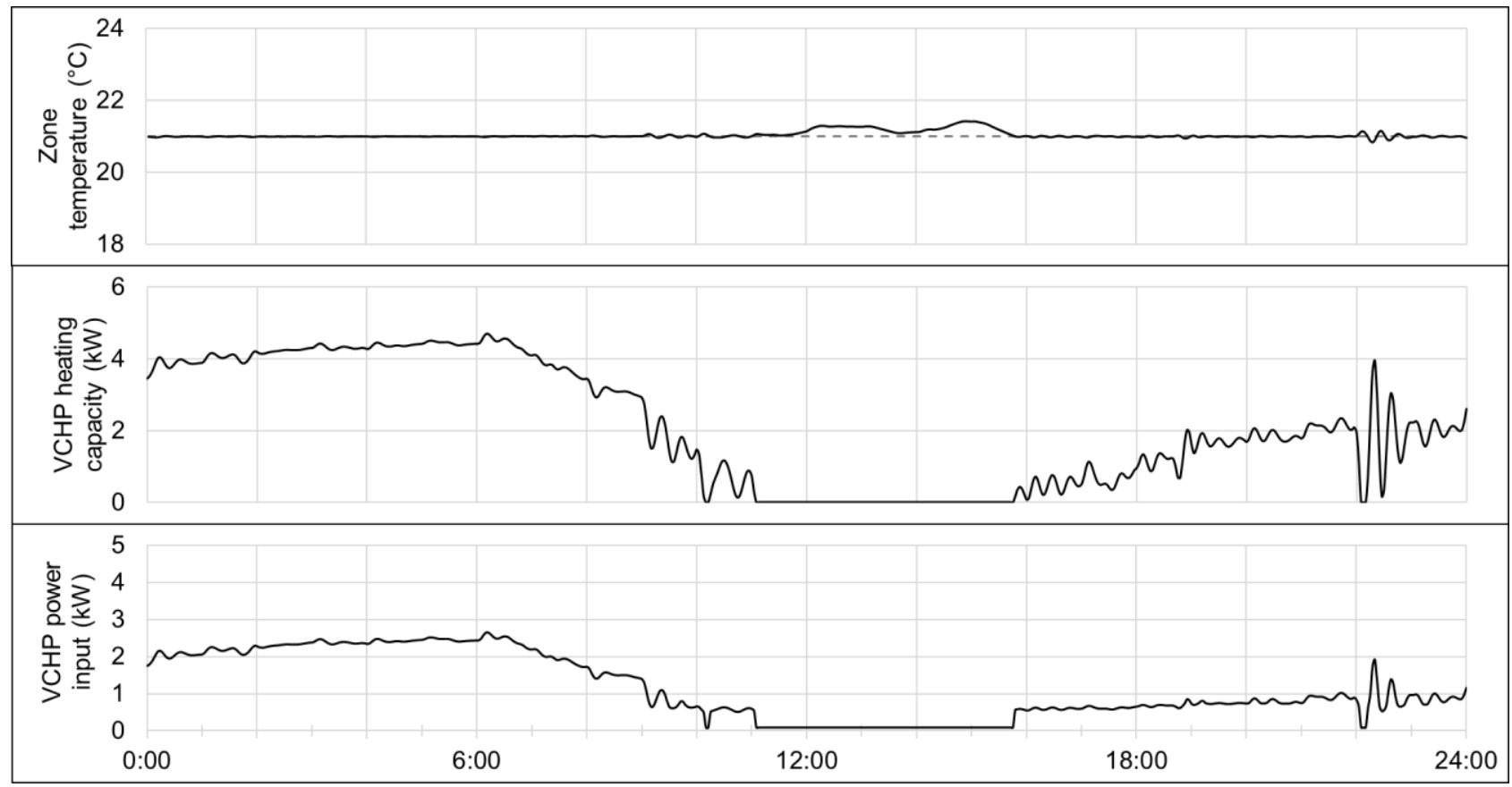

Figure 3: Simulation results for Montreal on March 11th using Type 954

More importantly, the VCHP power input closely follow the heating capacity and does not show periodic peaking consistent with compressor startup. Both models estimated a similar daily energy consumption for space heating (around $28 \mathrm{kWh}$ ), but without accounting for the important fluctuations in power draw associated with VCHPs startup and defrost, the peak power draw is drastically underestimated. The peak electrical demand over March $11^{\text {th }}$ was underestimated by $40 \%$ (2.6 kW for Type $954 \mathrm{vs} 4.3 \mathrm{~kW}$ for Type 3255) when using the 
simplistic PLR and performance curve approach. The difference in simulated peak loads between both modelling strategies seemed to be exacerbated at higher ambient air temperatures, when the VCHP exhibits cycling behaviour. Whereas the daily peak of $4.3 \mathrm{~kW}$ estimated with Type 3255 happened during cycling, the conventional modelling strategy reported a maximum electrical power of less than $2 \mathrm{~kW}$ during this period. Detailed component models like Type 3255 are essential in better assessing the grid impact of widespread adoption of electrically driven space-conditioning equipment.

\section{Conclusions \& future work}

Cold climate heat pumps with variable-capacity compressors show promising potential to deliver spaceconditioning energy savings. To better evaluate their performance and estimate these savings, an enhanced VCHP component model was developed building on the model of St-Onge (2018). This new model, TRNSYS Type 3255, incorporates key VCHP phenomena, including capacity and efficiency at different compressor speeds, and defrost and startup sequences which are not captured in existing heat pump models. Annual energy simulations were run by integrating the VCHP model in new construction housing models for five Canadian regions. The simulation results suggested that considerable reductions of the energy used for space heating and cooling could be achieved across Canada. Savings varied between $28 \%$ and $37 \%$ for the split-system VCHP (Halifax and Montreal) and between 51\% and 59\% for the centrally-ducted systems (Toronto, Vancouver and Whitehorse). Performance at shorter time scales was also examined, demonstrating the ability of the new model to better capture variable capacity compressor performance and the impacts of defrost and startup sequences.

A comparison with a conventional heat pump modelling strategy - where the load is perfectly met at every time step - showed that the peak power can be underestimated by as much as $40 \%$ using the more simplified approach. Accurately modelling short-term heat pump behaviours is an essential element in assessing the grid impact of widespread heat pump adoption, and a key contribution of the new enhanced model.

Future work will extend the testing of VCHP in cooling mode in order to obtain a complete performance map (with compressor speed dependence) under a variety of cooling loads and an extended range of outdoor temperatures - analogous to what was done for heating. Future work will also aim at providing a more detailed representation of defrost strategy. This includes providing model flexibility to vary the defrost duration and frequency based on outdoor conditions (air and coil temperatures, relative humidity).

\section{Acknowledgement}

The authors acknowledge the financial support of the Office of Energy Efficiency's Research and Development Energy Innovation Program.

\section{References}

Canadian Commission on Building and Fire Codes (CCBFC). (2015). National Energy Code of Canada for Buildings (NECB) 2015. Ottawa (CA).

Filliard, B., Guiavarch, A. and Peuportier, B. (2009) Performance Evaluation of an Air-to-Air Heat Pump Coupled with Temperate Air Sources Integrated Into a Dwelling. Proceedings of BS2009: 11th International Conference of IBPSA, Glasgow (SCT). July 27-30 2009.

Kegel M., Sunye R., Tamasauskas J. (2012). Life Cycle Cost Comparison and Optimisation of Different Heat Pump Systems in the Canadian Climate. Proceedings of eSim 2012: 7th Conference of IBPSA-Canada, Halifax (CA), May 1-4 2012.

Kegel, M., Tamasauskas, J. and Sunye, R. (2014). Integration and Evaluation of Innovative and Renewable Energy Technologies in a Canadian Midrise Apartment. In Proceedings of SSB2014: 9th International Conference on System Simulation in Buildings, Liège (BE), December 10-12 2014.

Kegel, M., Tamasauskas, J., Sunye, R. and Giguere, D. (2017). Heat Pump Water Heaters in the Canadian Residential Markets. In Proceedings of HPC 2017: 12th IEA Heat Pump Conference 2017, Rotterdam (NL), May 15-18 2017.

Klein S.A. et al. (2014). TRNSYS 17 - A TRaNsient SYstem Simulation program, user manual. University of Wisconsin-Madison, Solar Energy Laboratory, Madison (USA).

Mitsubishi Electric. (2017). P-Series and M-Series Engineering Manuals. Available at: http://mylinkdrive.com/. Last Accessed January 2019.

National Research Council of Canada (NRC) (2010). National Building Code of Canada. $13^{\text {th }}$ ed., Ottawa: NRC; ISBN 0-660-19975-7.

Natural Resources Canada (NRCan). (2018). Comprehensive Energy Use Database. Office of Energy Efficiency, NRCan, Ottawa (CA).

Sager, J., Mackintosh, T., St-Onge, G., McDonald, E. and Kegel, M. (2018). Detailed performance assessment of variable capacity inverter-driven cold climate air source heat pumps. In Proceedings of Cold Climate HVAC 2018: The 9th International Cold Climate Conference, Kiruna (SWE), March 12-15 2018.

St-Onge, G. (2018). Variable Capacity Mini-Split Air Source Heat Pump Model for TRNSYS. M.A.Sc thesis, École Polytechnique de Montréal, Montréal (CA).

Tamasauskas J., Kegel M., Sunye R. (2013). An Analysis of Deep Energy Retrofit Strategies in the Existing Canadian Residential Market. Proceedings of BS2013: $13^{\text {th }}$ International Conference of IBPSA, Chambery (FR). 25-28 August 2013. 